\title{
Selective Extraction of Rare Earth Elements from Phosphoric Acid by Ion Exchange Resins
}

\author{
Xavier Hérès ${ }^{1, *}$, Vincent Blet ${ }^{1}$, Patricia Di Natale ${ }^{1}$, Abla Ouaattou ${ }^{2}$, Hamid Mazouz ${ }^{2}$ (1), \\ Driss Dhiba ${ }^{2}$ and Frederic Cuer ${ }^{1}$ \\ 1 French Nuclear and Alternative Energies Commission (CEA), Nuclear Energy Division—CEA Marcoule, \\ Research Department of Mining and Fuel Recycling ProCesses (DMRC), BP 17171, F-30207 Bagnols sur Ceze, \\ France; Vincent.blet@cea.fr (V.B.); patricia.di-natale@cea.fr; (P.D.N.); frederic.cuer@cea.fr (F.C.) \\ 2 Research \& Development Direction, OCP SA., BP 118, Jorf Lasfar El Jadida, El Jadida 24000, Morocco; \\ Abla.OUAATTOU@ocpgroup.ma (A.O.); H.MAZOUZ@ocpgroup.ma (H.M.); \\ D.DHIBA@ocpgroup.ma (D.D.) \\ * Correspondence: xavier.heres@cea.fr; Tel.: +33-466-797-700
}

Received: 28 June 2018; Accepted: 25 August 2018; Published: 30 August 2018

\begin{abstract}
Rare earth elements (REE) are present at low concentrations (hundreds of ppm) in phosphoric acid solutions produced by the leaching of phosphate ores by sulfuric acid. The strongly acidic and complexing nature of this medium, as well as the presence of metallic impurities (including iron and uranium), require the development of a particularly cost effective process for the selective recovery of REE. Compared to the classical but costly solvent extraction, liquid-solid extraction using commercial chelating ion exchange resins could be an interesting alternative. Among the different resins tested in this paper (Tulsion CH-93, Purolite S940, Amberlite IRC-747, Lewatit TP-260, Lewatit VP OC 1026, Monophos, Diphonix,) the aminophosphonic IRC-747, and aminomethylphosphonic TP-260 are the most promising. Both of them present similar performances in terms of maximum sorption capacity estimated to be $1.8 \mathrm{meq} / \mathrm{g}$ dry resin and in adsorption kinetics, which appears to be best explained by a moving boundary model controlled by particle diffusion.
\end{abstract}

Keywords: phosphoric acid; rare-earth elements; separation; solid-liquid extraction; ion exchange resin

\section{Introduction}

As part of the framework agreement of R\&D collaboration between OCP SA and CEA, a study was conducted to evaluate the interest of the recovery of rare earth elements (REE) as by-product from the production of phosphoric acid from phosphate rocks. The leaching of the phosphorite ore with concentrated sulfuric acid ( 98 vol.\%) leads to phosphoric acid solutions with a concentration ranging from 4 to $5 \mathrm{~mol} / \mathrm{L}$, whose temperature can range from $60^{\circ} \mathrm{C}$ to $70{ }^{\circ} \mathrm{C}$, after phosphogypsum filtration. These filtered solutions contain rare earth elements (REE) (hundreds of ppm) that can be recovered if the economic balance is positive. Among separation techniques, the liquid-liquid extraction has been historically implemented because of the large flow rates involved. However, solid-phase extraction based on chelating ion exchange resins may be of interest for the following reasons:

- There is no risk of contamination of phosphoric acid with organic solvents, so no need for expensive post-acid treatment downstream of extraction [1].

- Solid supports are generally heat resistant [2,3]. This characteristic is very important because of relatively high operating temperatures of phosphoric acid solutions $\left(40-50{ }^{\circ} \mathrm{C}\right.$ after storage).

For low feed concentrations, cost of implementation (capital and operating costs) may be lower than in the case of solvent extraction that requires hundreds of mixer-settlers...

Some drawbacks could nevertheless be outlined [4]: 
- Resins may be sensitive to chemical degradation in concentrated phosphoric acid.

- Phenomena of swelling may lead to mechanical stresses during sorption-desorption.

- There is a risk of resin poisoning with some cationic impurities in large quantities such as iron, leading to a decrease in sorption capacity and/or selectivity.

Despite these possible limitations, a number of resins have been commercialized, making REE sorption a potential attractive alternative. As an illustration, the cost of an ion exchange (IX) process has recently been compared to that of a solvent extraction (SX) process in the case of uranium recovery from phosphoric acid [2]. Operating costs appear to be much lower for IX technology than those induced by SX ( $\$ 18$ instead of $\$ 32$ for the production of one pound of $\mathrm{U}_{3} \mathrm{O}_{8}$ ). However, this IX process has not been implemented at a commercial scale yet, but rather at a pilot scale for the extraction of uranium in phosphoric acid with sulfonic resins [5] or for the recovery of REE from leachates of uranium ores with sulfonic and phosphonic resins [6].

From an engineering point of view, the resin has to exhibit specific performances for an industrially viable IX extraction of REE from wet phosphoric acid:

- A high selectivity between REE and cationic impurities such as iron $\left(\mathrm{Fe}^{3+}\right)$, uranium (U(IV), $\mathrm{U}(\mathrm{VI})$ ) or thorium (Th(IV)), taking into account that $\mathrm{Fe}^{3+}$ is approximately 30 to 40 times more concentrated than REE in phosphoric acid solutions. Due to a similarity in extraction chemistry, $\mathrm{Fe}^{3+}$ and Th are often adsorbed onto chelating resins in preference to REE [7]. It should be noted that a first precipitation of $\mathrm{Fe}^{3+}$ is not an option since it could generate high losses in REE by co-precipitation [6].

- A good capability to bind the REE in highly concentrated $\mathrm{H}_{3} \mathrm{PO}_{4}$ (4 to $5 \mathrm{~mol} / \mathrm{L}$ ). A total ion exchange capacity greater than $2 \mathrm{meq} / \mathrm{g}$ of resin is generally sought ( $1 \mathrm{eq}=1 \mathrm{~mole} /$ valence). The higher the capacity the smaller the process and thus the investment cost.

- The kinetics of sorption and elution should be fast enough to limit the size of the columns.

- A mechanical, physical, and chemical stability over several cycles of extraction/elution will reduce the operating cost.

It is well known [8] that these performances are strongly related to:

- The nature of the matrix (copolymer), the structure and the degree of crosslinking, the nature and the number of fixed ionic (functional) groups.

- The presence of competitive cationic impurities such as $\mathrm{U}, \mathrm{Th}, \mathrm{Fe}^{3+}, \mathrm{Al}^{3+}, \mathrm{Ca}^{2+}, \mathrm{Mg}^{2+}, \ldots$ In that study it should be emphasized that, no $\mathrm{U}$ or Th is present in the OCP's genuine acid solutions due to a preliminary proprietary treatment.

- The nature and $\mathrm{pH}$ of the bulk acidic medium.

Based on these remarks, commercially available ion exchange resins have been selected for their potential capability to extract REE from high concentrated phosphoric acid. Some resins have already been tested in close conditions [9] but they exhibit a low yield of extraction $(<20 \%)$ when the phosphoric acid concentration is $5 \mathrm{~mol} / \mathrm{L}$. Moreover, most of the literature concerns other acidic media (hydrochloric, sulfuric, nitric ... ) and cannot be directly applied to such an acidic medium containing strong complexing phosphates. In that context, this paper aims at comparing promising commercial resins in view of the industrially viable valorization of REE contained in the highly concentrated phosphoric acid produced by OCP.

\section{Choice of the Resin}

Numerous functional groups such as dialkylphosphoric, phosphonic, phosphoric, iminodiacetic acids are known to be good REE chelatants $[7,10]$. Resins with similar functional groups are thus particularly interesting. More specifically, phosphorus-containing resins are widely used for preconcentration of transition metals, lanthanides, uranium, and thorium [11]. These cation 
exchangers contain either phosphate-OPO $(\mathrm{OH})$ or phosphonic- $\mathrm{PO}(\mathrm{OH})$ or phosphinic- $\mathrm{PO}(\mathrm{OH})$ $\mathrm{H}$ function. The stability of the aminophosphonic group was confirmed with Tulsion CH-93 resin: after 7 cycles of gadolinium (GdIII) extraction in phosphoric acid followed by quantitative elution with ammonium oxalate, $\mathrm{Gd}^{3+}$ extracted at the same yield of $70 \pm 1 \%$ [12]. Another advantage is the low sensitivity of phosphorus resins like Tulsion-CH-96 (phosphinic acid) or T-PAR (phosphoric acid) to the temperature [13]. Increasing the phosphoric acid temperature from $30^{\circ} \mathrm{C}$ to $70^{\circ} \mathrm{C}$ hardly modifies the REE extraction. Since this phenomenon has been observed on two types of phosphorus resins (with phosphinic or phosphoric functional groups), it is likely that resins with a phosphonic group should not be particularly heat sensitive too. This is confirmed by a uranium extraction study with Amberlite IRC747 resin between $40{ }^{\circ} \mathrm{C}$ and $60{ }^{\circ} \mathrm{C}$ [14].

The state-of-the-art literature has shown that commercial resins containing aminophosphonic groups (pattern (a) in Figure 1), such as the reference $\mathrm{CH}-93$ Tension provided by Thermax, Lewatit TP-260, Purolite S940 and Amberlite IRC747, exhibit high REE complexing ability. In order to test the phosphonic functional group without amine, the Diphonix resin manufactured by EiChrom Industries (pattern (c) in Figure 1) has also been selected. The Actinide-Resin B (pattern (d)) has also been tested because of its very high complexing power [15]. For the Lewatit VP OC 1026 resin (pattern (b) in Figure 1), the functional group (D2EHPA) is impregnated (by adsorption) in the crosslinked polystyrene divinylbenzene matrix. For the other resins the functional groups are covalently bonded to the cross-linked polystyrene divinylbenzene matrix.

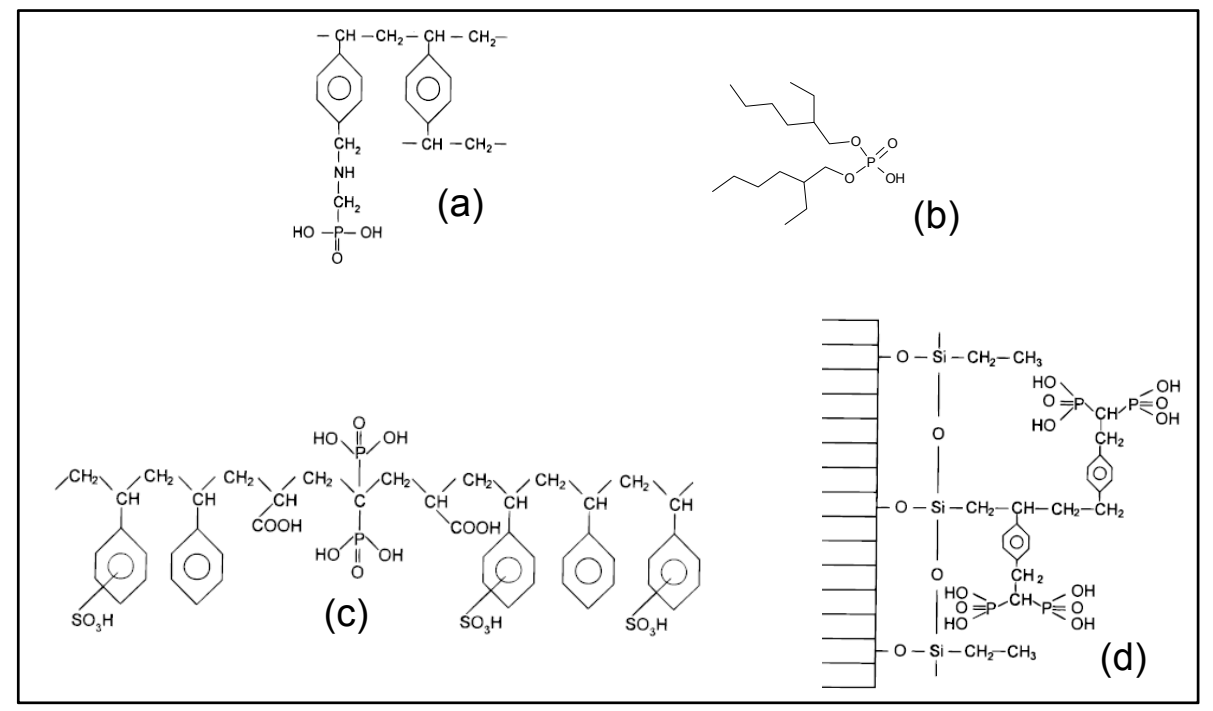

Figure 1. Chemical structure of functional groups present in various commercial resins potentially effective for extracting rare earth elements (REE) in a phosphoric medium. (a) Tulsion CH-93, Purolite S940, Amberlite IRC-747 and Lewatit TP-260, (b) Lewatit VP OC 1026, (c) Diphonix, (d) Actinide-CU (reproduced from [15], with permission of American Chemical Society, 1998).

\section{Materials and Methods}

Tulsion CH-93 was supplied by Thermax (Pune, India), Diphonix and Actinide-CU were delivered by EiChrom Industries (Bruz, France), Amberlite IRC 747, and Purolite S940 were from Dow France SAS (Chauny, France) and Purolite International (Paris, France), Lanxess Energizing Chemistry (Courbevoie, France), supplied Lewatit TP-260 and VP OC 1026. These resins have been preconditioned in deionized (DI) water. They are all weak acid ion exchangers and are supplied as powders composed of spherical beads. Their main characteristics are reported in Table 1.

It is worth mentioning that preliminary conditioning of $\mathrm{Na}^{+}$-resins under $\mathrm{H}^{+}$ionic form has been proved to have no measurable impact on the extraction efficiency of the resins for all the REE and 
impurities present in the tested phosphoric acid solutions. The high acidity of the phosphoric acid solutions compared to the low concentrations in impurities favors the complete $\mathrm{H}^{+} / \mathrm{Na}^{+}$exchange in the resins before REE extraction. The variation in the concentration of $\mathrm{H}^{+}$in the bulk of the acid solution due to either the REE adsorption or the $\mathrm{Na}^{+}$exchange is negligible when compared to its initial concentration in the phosphoric acid solution.

\subsection{Physicochemical Properties of Resins}

Specific surface areas of resins were determined by measuring the nitrogen adsorption/desorption isotherm. The latter is represented in the form of a graph giving the adsorbed quantity per gram of adsorbent as a function of the equilibrium relative pressure (ratio of the equilibrium pressure of the adsorbable gas and its saturation vapor pressure). The plot of this isotherm allows, in the zone of relative pressure between 0.3 and 0.8 , to determine specific surface areas using the model Brunauer, Emmett, Teller (BET). This isotherm also gives pore size distribution with the model Barret Joyner, Halenda (BJH). Table 1 gathers the measurements of specific surface areas and pore sizes according to the BET and BJH models respectively.

Table 1. Main characteristics of the resins tested in this study.

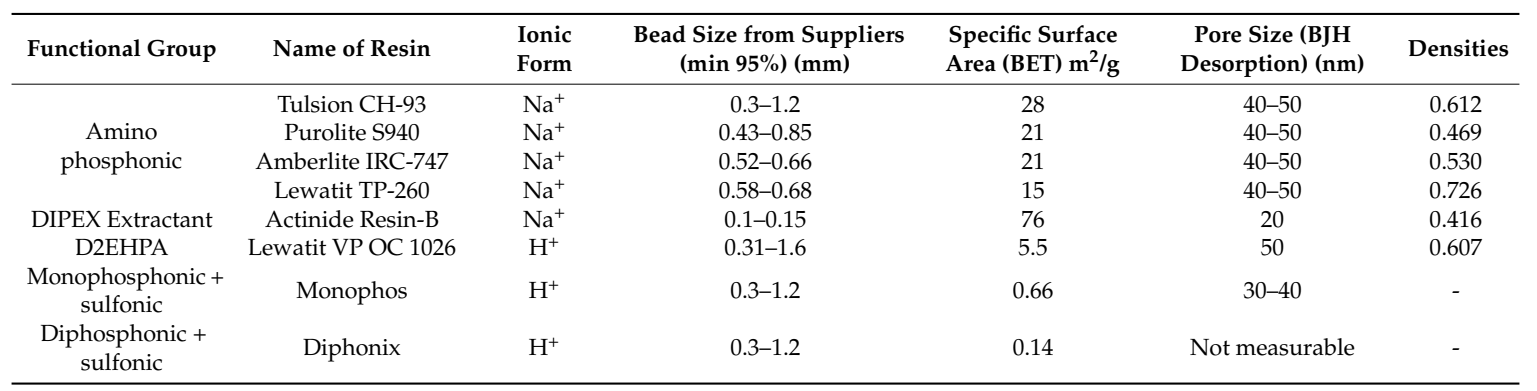

A large specific surface area (i.e., $>15 \mathrm{~m}^{2} / \mathrm{g}$ ) and pore diameters between 2 and $50 \mathrm{~nm}$ are sought in order, on the one hand, to maximize the ion exchange capacity and, on the other hand, to promote the diffusion of solute in the complexation sites located in the core of the material. Resins with aminophosphonic function (CH-93, S940, IRC-747, TP-260) have specific surface areas between 16 and $28 \mathrm{~m}^{2} / \mathrm{g}$. Actinide Resin B has a surface area two to three times higher while VP OC 1026 leads to a lower value of $5.5 \mathrm{~m}^{2} / \mathrm{g}$. All the resins containing sulfonic groups have very low specific surface areas $\left(<1 \mathrm{~m}^{2} / \mathrm{g}\right)$, which could limit the accessibility to the pores. Overall, the resins not containing sulfonic groups show specific surface areas and pore sizes that meet targeted characteristics of a mesoporous resin. Nevertheless, BET and BJH measurements are not sufficient to compare the resins in terms of exchange capacity and specific experiment have been conducted in Section 4.3.

\subsection{Composition of Aqueous Solutions}

Table 2 gives the composition in REE of the solutions used in this study. J0 and J1 are genuine phosphoric acid solutions produced by OCP SA (Jorf Lasfar El Jadida, Morocco). Both solutions have been analyzed by Inductively Coupled Plasma-mass Spectrometry (ICP-MS) instrument (ThermoFischer Scientific, Villebon-sur-Yvette, France) (error $<5 \%$ ). From these measurements synthetic solutions (called REH and REOCP, composition in Table 2) have been made by solubilizing the major REE (>mg/L in bold in the J1 column) at a higher concentration than in the genuine samples. This procedure enables the use of ICP-AES (Horiba Jobin Yvon SAS, Longjumeau, France) measurements with a sufficient analytical sensitivity (error $<5 \%$ ) while minimizing the measurement time. In order to be representative of the genuine solution, the REE were solubilized in $4.2 \mathrm{~mol} / \mathrm{L}$ phosphoric acid, from their metallic form for La, Nd, Gd, Dy, Er, Yb and from their oxide form for Sc and Y. REE are solubilized as trivalent cations. The difference in REH and REOCP solutions lies in the presence of major interfering metallic impurities in the REOCP solution. In order to be similar 
to a genuine solution, vanadium, magnesium, and zinc were solubilized from their metallic form in $4.2 \mathrm{~mol} / \mathrm{L}$ phosphoric acid, while the iron was prepared from its hydrate phosphate solid form. Aluminum was solubilized from its hydroxide form and calcium from carbonate. The error in the measurement of these impurities is $\pm 5 \%$ in the whole range of concentrations whatever the technique (ICP-MS or ICP-AES). J0 has been used for kinetic studies while J1, JSYNT, REH and REOCP have been used for extraction yields measurement in batch experiments

Ion exchange resins generally have greater selectivity for ions with increasing valence or charge. Among the ions with the same charge, higher affinity is observed for ions with higher atomic number $\mathrm{Z}$ and the extraction efficiency decreases with increasing REE ionic radius IR [9]. It is worth mentioning that the chosen major REE in the synthetic solution have ionic radii that cover the whole range of the actual REE ionic radii (see Table 2).

Table 2. Composition in REE (mg/L) and in major interfering impurities (in italic, $g / L$ ) of the phosphoric acid solutions (J0-J1-JSYNT, REH, REOCP) used in the experiments with corresponding ionic radii IR (data from [16])and ratio $\mathrm{Z} / \mathrm{IR}$ where $\mathrm{Z}$ is the atomic number of the REE.

\begin{tabular}{|c|c|c|c|c|c|c|c|}
\hline $\mathrm{C}_{\mathrm{M}}(\mathrm{mg} / \mathrm{L})$ or $(g / L)$ & J0 & J1 & REH REOCP & JSYNT & Ionic Radius [16] (A) & $\mathbf{Z}$ & $\mathrm{Z} / \mathrm{IR}\left(\mathrm{A}^{-1}\right)$ \\
\hline $\mathrm{Y}$ & 24.6 & 37 & 72 & 6.8 & 0.89 & 39 & 44 \\
\hline $\operatorname{Pr}$ & 1.2 & 1.3 & - & - & 1.01 & 59 & 58 \\
\hline $\mathrm{Nd}$ & 3.1 & 5.8 & 54 & 5.0 & 1.00 & 60 & 60 \\
\hline $\mathrm{Sm}$ & 0.9 & 1.5 & - & - & 0.96 & 62 & 65 \\
\hline $\mathrm{Tb}$ & 0.4 & 0.4 & - & - & 0.92 & 65 & 71 \\
\hline Dy & 1.9 & 3.0 & 74 & 6.8 & 0.91 & 66 & 73 \\
\hline Ho & 0.7 & 0.8 & - & - & 0.89 & 67 & 75 \\
\hline $\mathrm{Er}$ & 1.9 & 2.8 & 73 & 6.7 & 0.88 & 68 & 77 \\
\hline $\mathrm{Tm}$ & 0.5 & 0.5 & - & - & 0.87 & 69 & 79 \\
\hline $\mathrm{Ca}$ & 0.8 & 0.8 & 1.0 & & - & - & - \\
\hline $\mathrm{Fe}$ & 1.7 & 1.4 & 1.4 & 1.3 & - & - & - \\
\hline$M g$ & 3.9 & 4.3 & 4.8 & - & - & - & - \\
\hline$V$ & 0.12 & 0.11 & 0.1 & - & - & - & - \\
\hline $\mathrm{Zn}$ & 0.22 & 0.21 & 0.30 & - & - & - & - \\
\hline$\left[\mathrm{H}_{3} \mathrm{PO}_{4}\right](\mathrm{mol} / \mathrm{L})$ & 3.9 & 3.8 & 4.2 & 4.2 & - & - & - \\
\hline
\end{tabular}

\subsection{Experimental Protocol for Batch Tests (Extraction and Elution)}

Sorption or elution experiments are carried out in $15 \mathrm{~mL}$ or $2 \mathrm{~mL}$ tubes arranged horizontally on a stainless steel support with a double jacket to keep the temperature constant, with 1 or $10 \mathrm{~mL}$ of aqueous phosphoric acid solutions and 50 or $100 \mathrm{mg}$ of resin previously dried overnight in an oven at $60{ }^{\circ} \mathrm{C}$. Tubes are stirred at $50{ }^{\circ} \mathrm{C}$ (respectively $25^{\circ} \mathrm{C}$ for elution studies) in Vibrax for $3 \mathrm{~h}$ or in Ecotron for $24 \mathrm{~h}$.

Once stirring is complete, the aqueous solutions are filtered under vacuum using a $0.45 \mu \mathrm{m}$ filter. The tube and filter are washed with DI water to remove the impregnated aqueous extractant solution and then the powder is dried in an oven at $60^{\circ} \mathrm{C}$ overnight.

Results obtained after stirring for 3 or $24 \mathrm{~h}$ were similar, thus indicating that the sorption or elution equilibrium has been reached for all experiments.

\subsection{ICP-AES Analysis Protocol}

ICP-AES is a very sensitive elemental analysis technique used to quantify the total amount of elements in aqueous solution. The analysis is carried out on samples diluted in $0.42 \mathrm{~mol} / \mathrm{L}$ phosphoric acid. The device used is an Ultima-2 brand Horiba Jobin Yvon SAS. 
The wavelengths chosen for the ICP-AES are as follows (in nm): Al 396.152-Ca 393.366-Ce 413.765-Dy 394.469-Er 390.631-Fe 259.837—Gd 301.014-La 399.575-Mg 518.362—Nd 406.109—Sc 337.215-V 311.838-Y 377.433-Yb 328.937-Zn 206.200.

$\mathrm{Al}, \mathrm{Ca}, \mathrm{Fe}, \mathrm{Mg}, \mathrm{V}$, and $\mathrm{Zn}$ are calibrated in the range 1 to $10 \mathrm{mg} / \mathrm{L}(0-1-3-5-10 \mathrm{mg} / \mathrm{L})$. Ce, Dy, Er, Gd, La, Nd, Sc, Y, and $\mathrm{Yb}$ are calibrated from 0.1 to $1 \mathrm{mg} / \mathrm{L}(0-0.1-0.3-0.5-1 \mathrm{mg} / \mathrm{L})$.

The error in concentration measurement has been estimated to be $\pm 5 \%$ taking into account the dilution.

\subsection{Mineralization Protocol}

The mineralization operation consists in dissolving solids or decomposing organic material to obtain an aqueous solution for elemental analyses by ICP-AES. The device used is an Ethos One from Milestone. It comprises an oven, inside of which is placed a rotor comprising 10 segments each containing a $100 \mathrm{~mL}$ reactor. The microwave oven serves to improve the dissolution kinetics of solids or decomposition of organic matter. The reference reactor contains a thermowell in which the thermocouple plunges to pilot the reaction. A minimum of $8 \mathrm{~mL}$ of solution with at least $4 \mathrm{~mL}$ of $\mathrm{HNO}_{3} 69 \mathrm{wt} \%$ (15.4 mol/L) and $4 \mathrm{~mL}$ of hydrogen peroxide $35 \mathrm{wt}$ \% are introduced into the reactors with $50 \mathrm{mg}$ of resin. Mineralization consists of three main steps:

1. Temperature increase: gradient $10^{\circ} \mathrm{C} / \mathrm{min}$ for $20 \mathrm{~min}$ up to $200^{\circ} \mathrm{C}$ and 100 bars at maximum power $(1000 \mathrm{~W})$.

2. Temperature step: $10 \mathrm{~min}$.

3. Cooling: 30 min during which a forced convection with a fan occurs in the oven.

The reactor is then rinsed with $20 \mathrm{~mL}$ of DI water recovered in a volumetric flask. After dilution in $\mathrm{H}_{3} \mathrm{PO}_{4} 0.42 \mathrm{~mol} / \mathrm{L}$, mineralization solutions are analyzed by ICP-AES.

\subsection{Sorption Yields $Y_{M}$ and $R_{M}$ of a Cation $M$}

Sorption yield corresponds to the amount of resin-fixed cations relative to the amount initially present in solution. Two calculation modes can be performed:

- By balancing the concentrations (in $\mathrm{mg} / \mathrm{L})$ in aqueous phase before $\left(C_{\mathrm{M} \text {-ini }}\right)$ and after extraction $\left(C_{\mathrm{M} \text {-end }}\right)$ :

$$
Y_{\mathrm{M}}(\text { extraction })=\left(C_{\mathrm{M} \text {-ini }}-C_{\mathrm{M} \text {-end }}\right) / C_{\mathrm{M} \text {-ini }}
$$

- By balancing the masses of cation $M$ in the aqueous phase before extraction and fixed onto the resin. This last mass is determined by the concentration of the mineralization solution, $\mathrm{C}_{\mathrm{M}-\operatorname{miner}}(\mathrm{mg} / \mathrm{L})$, and by the knowledge of the total masses and volumes used for the extraction $\left(m_{\text {ext }}(\mathrm{mg}), V_{\text {ext }}(\mathrm{L})\right)$ and the mineralization $\left(m_{\text {miner }}(\mathrm{mg}), V_{\text {miner }}(\mathrm{L})\right)$ :

$$
R_{\mathrm{M}}(\text { extraction })=\left(C_{\mathrm{M}-\text { miner }} V_{\text {miner }}\right) /\left(C_{\mathrm{M} \text {-ini }} V_{\text {ext }}\right)\left(m_{\text {ext }} / m_{\text {miner }}\right)
$$

The errors on $Y_{M}$ and $R_{M}$ are estimated to be $\pm 15 \%$.

\subsection{Mass of Adsorbed Cation Per Gram of Dry Resin $\left(X_{M}\right)$}

Two calculation modes can be performed:

- Taking into account initial and post-extraction concentrations in the aqueous phase:

$$
X_{\mathrm{M}}=\left(C_{\mathrm{M} \text {-ini }}-C_{\mathrm{M} \text {-end }}\right) V_{\text {ext }} / m_{\text {ext }}
$$

The error on $X_{M}$ is estimated to be $\pm 15 \%$. 
- $\quad$ By direct mineralization of the resin trapping the cation:

$$
X_{\mathrm{M} \text {-fixed }}=C_{\mathrm{M} \text {-miner }} V_{\text {miner }} / m_{\text {miner }}
$$

The error on $X_{M}$ based on that calculation is estimated to be $\pm 10 \%$. It is worth mentioning that $X_{M}$ is often referred to as the resin adsorption capacity for cation $M$.

\subsection{Experimental Protocol for the Kinetic Studies}

These studies have been performed using lab-scale columns in which a resin bed is put. Before starting the REE extraction from phosphoric acid, the resin was conditioned according to the following steps:

- Washing the resin with demineralized water.

- Conditioning the resin under $\mathrm{H}^{+}$ionic form using sulfuric acid.

- Washing the resin to remove the remaining sulfuric acid.

Then the real phosphoric acid is continuously passed through the resin bed whose volume (BV) is $50 \mathrm{~mL}$ under a constant flowrate of $5 \mathrm{~mL} / \mathrm{min}(0.1 \mathrm{BV} / \mathrm{min})$ so that the residence time inside the resin bed is $10 \mathrm{~min}$. Every $10 \mathrm{~min}$., a sample of the phosphoric acid is collected at the outlet of the column and analyzed by ICP-AES (error 5\%). This sampling has been done over $90 \mathrm{~min}$. (i.e., $9 \mathrm{BV}$ ).

\subsection{Mass of Eluted Cations Per Gram of Dry Resin ( $\left.X_{M-e l u t e d}\right)$}

The calculation takes into account only the mass of resin used for the elution $m_{\text {elution}}$, the aqueous elution volume $V_{\text {elution }}(\mathrm{L})$ and the concentration of the cation in aqueous phase after elution $\mathrm{C}_{\text {M-elution }}(\mathrm{mg} / \mathrm{L})$

$$
X_{\text {M eluted }}=C_{\text {M-elution }} V_{\text {elution }} / m_{\text {elution }}
$$

The error on $X_{M}$ based on that calculation is estimated to be $\pm 10 \%$.

\section{Results and Discussion}

\subsection{Extraction of REE from Synthetic Solutions REH and REOCP}

In order to estimate the extraction efficiency of REE by resins, experiments were carried out following the protocol reported in Section 3.3 with $100 \mathrm{mg}$ of resins contacted by $10 \mathrm{~mL}$ of REH or REOCP solution. Some of the resins were destroyed by mineralization and the resulting aqueous phases analyzed by ICP-AES. Sorption yields at $50{ }^{\circ} \mathrm{C}$ (respectively quantities of REE fixed on one gram dry resin) are reported in Figure 2 (resp. Figure 3) as functions of Z/IR and in Figure 4 as functions of IR.

Within the margin of error $(10 \%$ or $15 \%)$, results deduced from the mineralization are consistent with calculations from aqueous phases, thus validating the mineralization protocol and the good accuracy of the ICP-AES measurement. The deviation between both extraction yields is generally less than $15 \%$, except for the VP OC 1026 resin, which is possibly due to the use of a hydrated resin, hence an overestimation of the mineralized solid mass. In the following, only aqueous concentrations have been considered. 


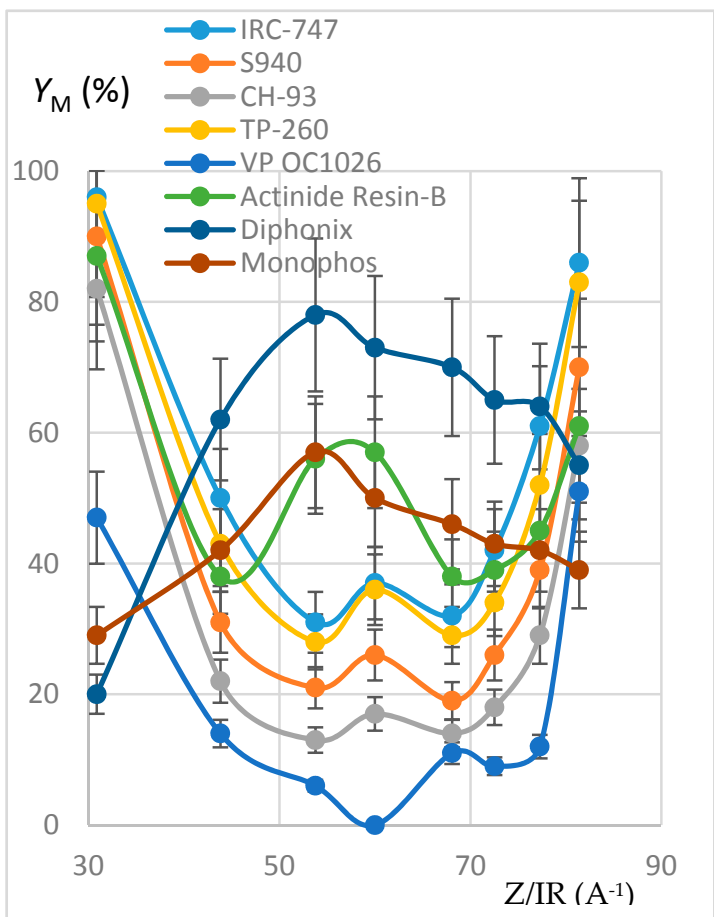

(a)

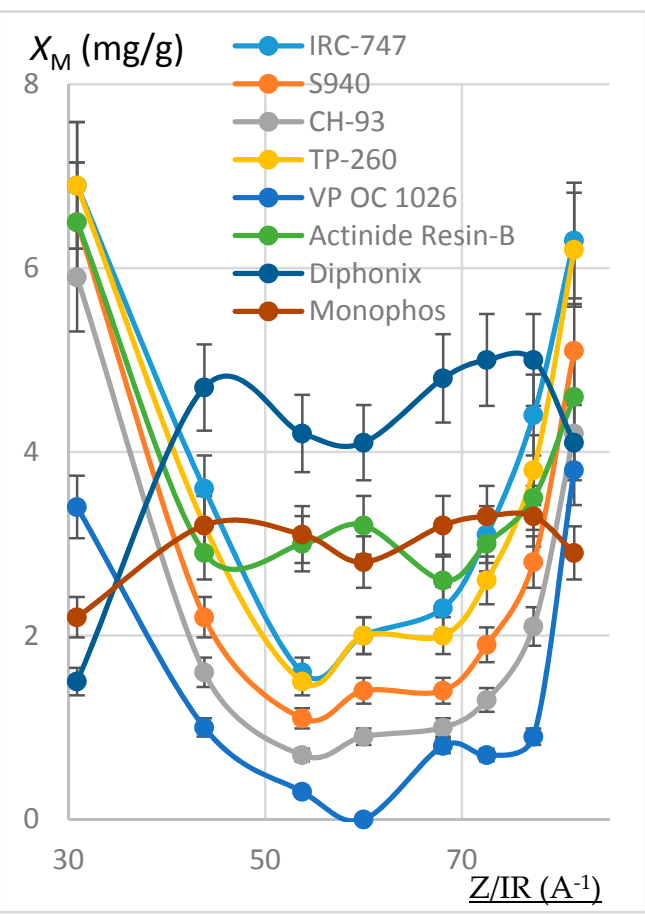

(b)

Figure 2. (a) Plot of $Y_{M}(\%)$ as a function of $Z / I R\left(A^{-1}\right)$. REH solution. Error bars $\pm 15 \%$. (b) Plot of $X_{\mathrm{M}}(\mathrm{mg} / \mathrm{g})$ as a function of $\mathrm{Z} / \mathrm{IR}\left(\mathrm{A}^{-1}\right)$. REH solution. Error bars $\pm 10 \%$.

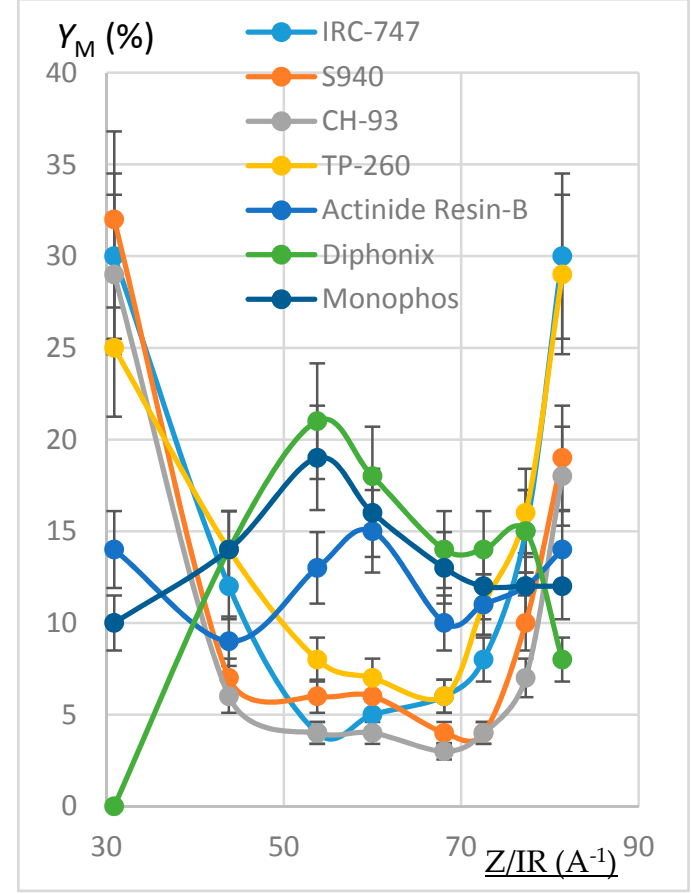

(a)

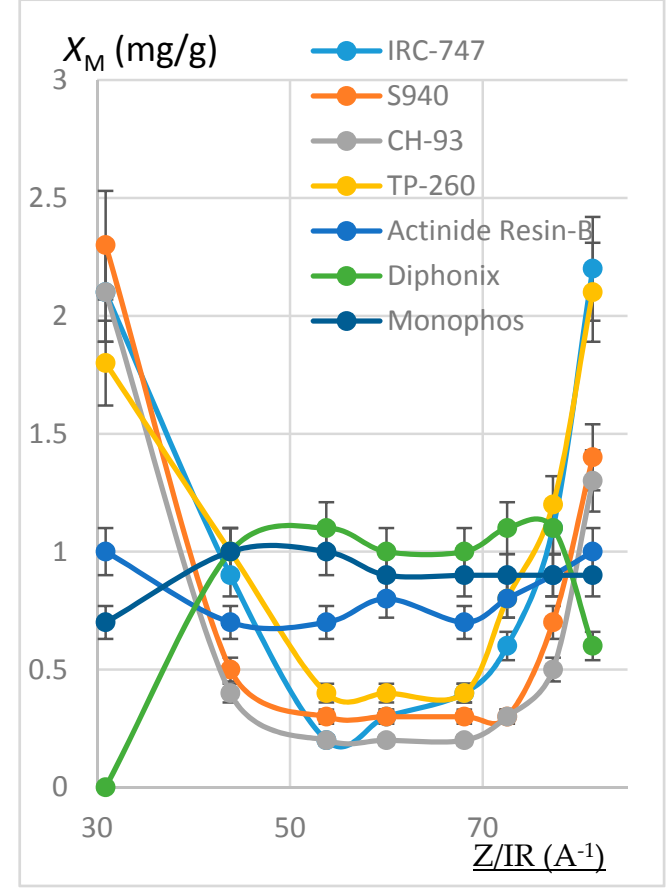

(b)

Figure 3. (a) Plot of $Y_{M}(\%)$ as a function of $Z / I R\left(A^{-1}\right)$. REOCP solution. Error bars $\pm 15 \%$. (b) Plot of $X_{\mathrm{M}}(\mathrm{mg} / \mathrm{g})$ as a function of $\mathrm{Z} / \mathrm{IR}\left(\mathrm{A}^{-1}\right)$. REOCP solution. Error bars $\pm 10 \%$. 


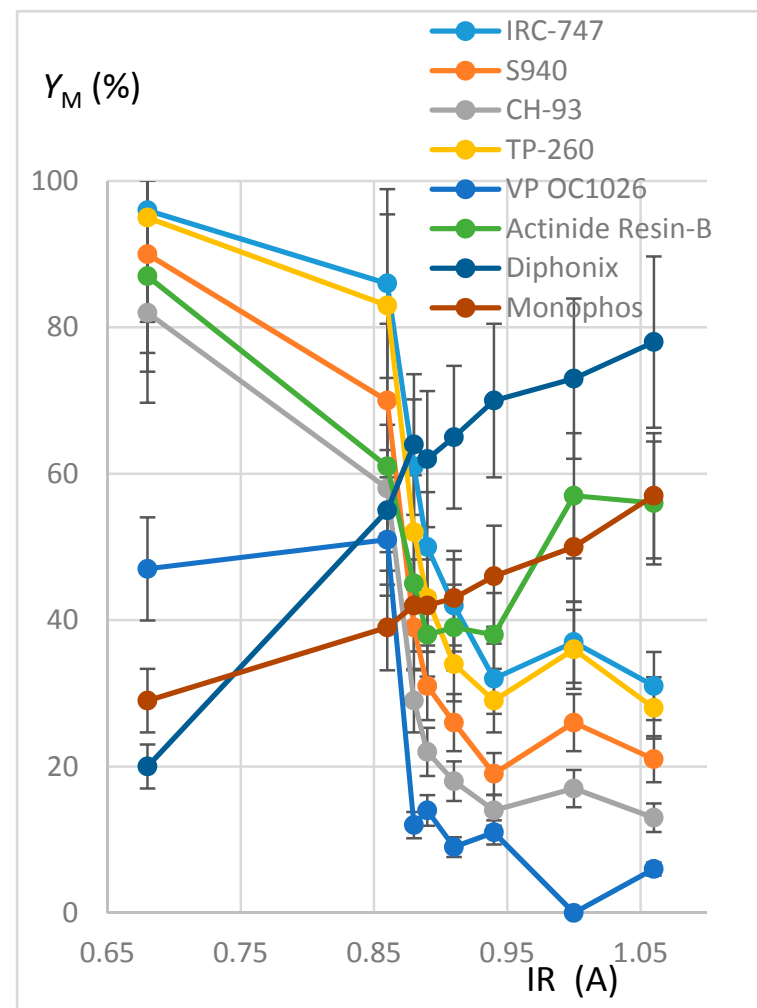

(a)

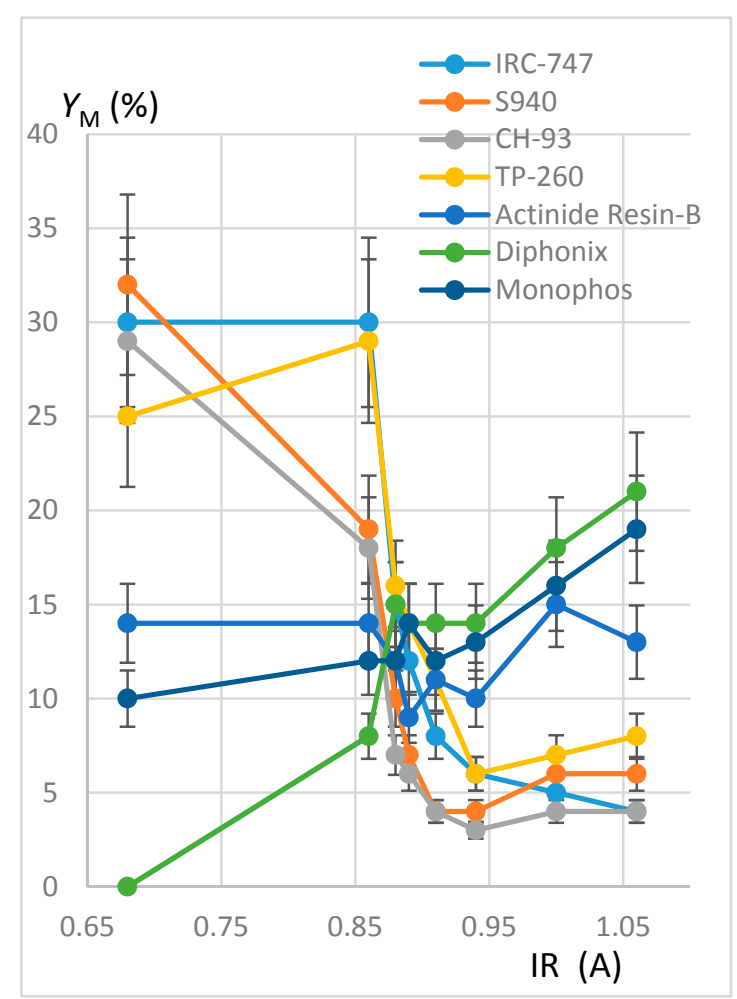

(b)

Figure 4. (a) Plot of $Y_{M}(\%)$ as a function of IR (A). REH solution. Error bars $\pm 15 \%$. (b) Plot of $Y_{M}(\%)$ as a function of IR (A). REOCP solution. Error bars $\pm 15 \%$.

It can be noticed that each resin maintains the same behavior towards the REE extraction when the impurities are present or not in the synthetic REH and REOCP solutions:

- The behavior of the aminophosphonic resins IRC-747, S940, CH-93, and TP-260 is similar: extraction decreases when $\mathrm{Z} / \mathrm{IR}$ increases from the scandium up to a plateau constituted by the group of $\mathrm{La}, \mathrm{Nd}, \mathrm{Gd}$, and then increases with $\mathrm{Z} / \mathrm{IR}$ from $\mathrm{Dy}$ to $\mathrm{Yb}$. It is worth noting that the efficiency of extraction (see Figure 4) decreases with IR similarly to that observed with $\mathrm{CH}-93$ resins $[12,13,17]$ or with phosphorus extractants [18], for example dialkylphosphinic acid CYANEX 272 [19] or di(2-ethylhexyl)phosphoric acid D2EHPA [20]).

- Without impurities in the phosphoric acid solution, the VP-OC-1026 resin on which the D2EHPA is adsorbed behaves similarly with the aminophosphonic resins but with a lower sorption efficiency.

- Without impurities, the extraction efficiency of Actinide Resin-B is not clearly related to Z/IR or to IR (see Figure 4). The presence of impurities flattens the extraction efficiency, which becomes nearly constant between $10 \%$ and $15 \%$ for all of the REE.

- The presence of a sulfonic group together with an alkylphosphonic function in the Diphonix and Monophos resins results in an inverted behavior compared to the above resins: the extraction efficiency increases as Z/IR increases from the scandium to the neodymium and then decreases for the highest Z/IR although it continuously increases with IR (see Figures 2-4). Despite their low specific surface area compared to the tested aminophosphonic resins (see Table 1) the Diphonix and Monophos resins extract REE in the same order of magnitude (from 10 to $20 \%$ except for scandium and ytterbium for the Diphonix). It is then probable that the number of accessible sites of complexing functions per gram of resin is higher for Diphonix and Monophos than for the other resins. 
In a more general manner, these results highlight the influence of the atomic number on the extraction affinity of the resins towards the REE and of the particular behavior of Diphonix/Monophos resins compared to the others.

Finally, the total masses of extracted REE and impurities are shown in Figure 5 for each resin together with the mass of the extracted iron. Within the margin of errors, all the resins have loaded the same mass of REE (about $7 \mathrm{mg} / \mathrm{g}$ ), except for CH-93 whose loaded mass is smaller than the others. With aminophosphonic resins (IRC-747, TP-260, S940 and CH-93) iron is the most extracted element that extraction corresponding to $62-84 \%$ of all the moles of cations sorbed onto these resins. The other resins extract less iron but much more magnesium, which also limits the sorption of REE. Overall, IRC-747, TP-260, and Diphonix/Monophos prove to be the most effective for extracting heavy REE and scandium: approximately $0.07-0.08$ millimole of REE per gram of dry resin is fixed. Compared to the total mass extracted in REE of about 0.3 millimole per gram of resins without impurities the competition with iron, aluminum, and magnesium reduces by a factor of four the total mass of REE extracted from a representative OCP phosphoric acid.

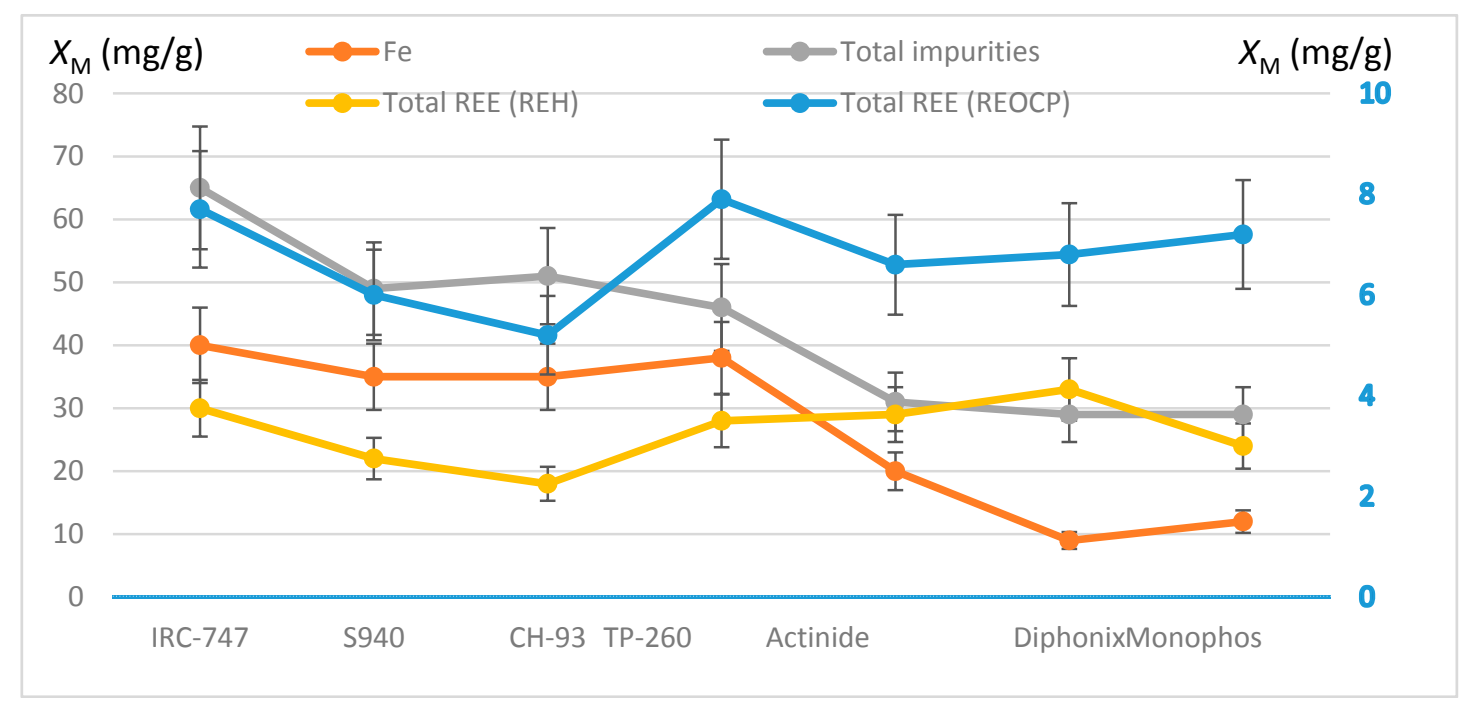

Figure 5. Comparison of total REE uptakes in the presence of impurities (REOCP synthetic solution, right $y$-axis) or not (REH synthetic solution, left $y$-axis). Plots of total impurities and iron uptakes (left $y$-axis) for the different resins. Error bars $\pm 15 \%$.

\subsection{Extraction of REE from JSYNT and J1 OCP Phosphoric Acid Solutions}

In order to quantify the lone interference of iron in the REE extraction the synthetic JSYNT solution has been made with concentrations of iron and REE close to those of the genuine J1 solution (see Table 2). From the preceding results, IRC-747 and TP-260 resins have been chosen due to their good affinities towards REE. They have been put in $2 \mathrm{~mL}$ tubes with $50 \mathrm{mg}$ of resins (see protocol in Section 3.3). Sorption yields $Y_{M}$ and the masses of elements $X_{M}$ trapped onto one gram of dry resin are illustrated in Figure $6 \mathrm{a}, \mathrm{b}$ respectively. $X_{\mathrm{M}}$ values have been calculated based on the difference in aqueous concentrations before and after extraction.

It is worth mentioning that the error in $Y_{M}$ is about $15 \%$ so that the deviations between J1 and JSYNT for IRC 747 are significant while the extraction yields for IRC 747 and TP260 are within the margin of error. These remarks hold for $\mathrm{X}_{\mathrm{M}}$ for which the error is estimated to be around $10 \%$. 


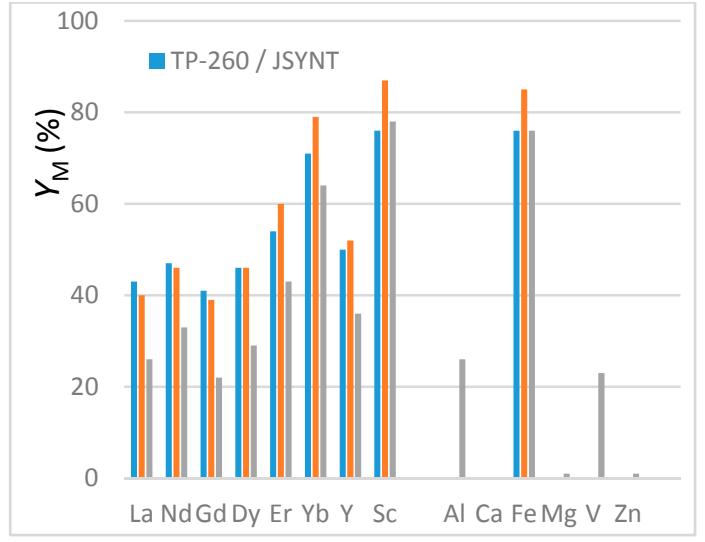

(a)

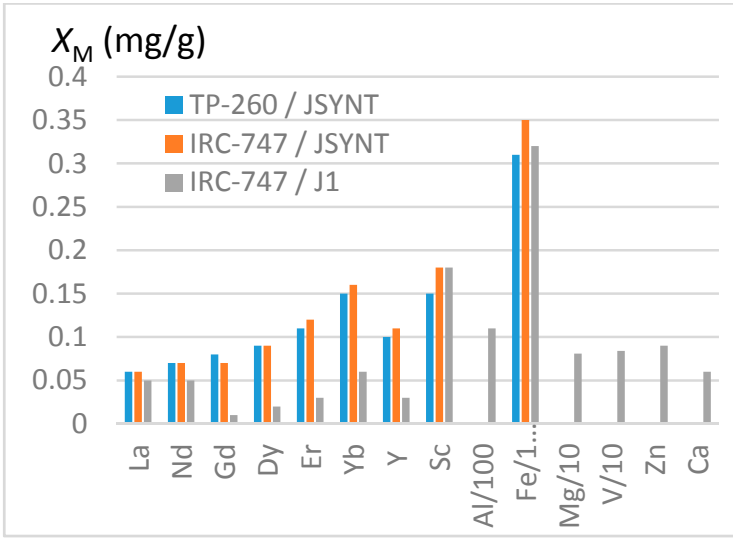

(b)

Figure 6. (a) Extraction yields $Y_{M}$ from JSYNT and J1 solutions. (b) Masses $X_{M}(\mathrm{mg} / \mathrm{g}$ ) of REE and impurities fixed in one gram of dry resin. Note that the fixed masses of impurities are divided by $100(\mathrm{Al}, \mathrm{Fe})$ or by $10(\mathrm{Mg}, \mathrm{V})$.

As previously noticed, iron is extracted with the same efficiency than scandium, the most extracted REE. The extraction yields are higher here because of a ratio of resin mass to aqueous volume higher than previously used $(50 \mathrm{mg} / 1.5 \mathrm{~mL}$ instead of $100 \mathrm{mg} / 10 \mathrm{~mL})$. Aluminum and vanadium are extracted with the same efficiency as light REE (La, $\mathrm{Nd}$ and Dy), which leads to a significant amount of these impurities trapped in the resins. It is worth mentioning that these efficiencies are coherent with those reported by Rhadika et al. [12] for the aminophophonic acid resin Tulson- $\mathrm{CH}$ 93. However, when expressed as $X_{M}$, these results highlight the cumulative deleterious influence of metallic impurities (notably Fe and $\mathrm{Al}$ ) on the REE extraction from genuine phosphoric acid. As an illustration, IRC-747 and TP-260 extract 0.009 millimole of total REE per gram of dry resin compared to about 0.6 millimole of iron from J1.

\subsection{Adsorption Isotherm of Er}

Erbium is one of the heavy REE contained in OCP phosphoric acid that is readily extracted by IRC-747 or TP-260 resins. For estimating the ion exchange capacity of the resins, erbium extraction tests were carried out in $15 \mathrm{~mL}$ tubes with $100 \mathrm{mg}$ of resins previously dried overnight in an oven at $60{ }^{\circ} \mathrm{C}$, and $10 \mathrm{~mL}$ of aqueous solution containing variable concentrations of erbium dissolved in pure phosphoric acid at $4.2 \mathrm{~mol} / \mathrm{L}$ (see Section 3.3).

The linearized Langmuir adsorption isotherm is expressed by the following equation [21]:

$$
\frac{C_{e q}}{X}=\frac{1}{b X_{m}}+\frac{C_{e q}}{X_{m}}
$$

where $C_{e q}$ is the concentration of erbium at equilibrium in aqueous phase $(\mathrm{mg} / \mathrm{L}), X$ is the amount of Er extracted by IRC-747 or TP-260 (mg/g), $b$ is the Langmuir constant $(\mathrm{L} / \mathrm{mg})$, and $X_{m}$ is the maximum adsorption capacity $(\mathrm{mg} / \mathrm{g})$. A very small value of Langmuir constant could be correlated to favorable adsorption thermodynamics. Figure 7 proves that the experimental adsorption isotherms of Er using the above resins fit very well the linearized Langmuir adsorption isotherm. The experimental capacity $X_{m}$ and $b$ are then obtained from slope and intercept of the straight lines shown in Figure 3. According to this model, the absorption of metal ions occurs on a homogeneous surface by monolayer adsorption and there is no interaction between the sorbed species. 


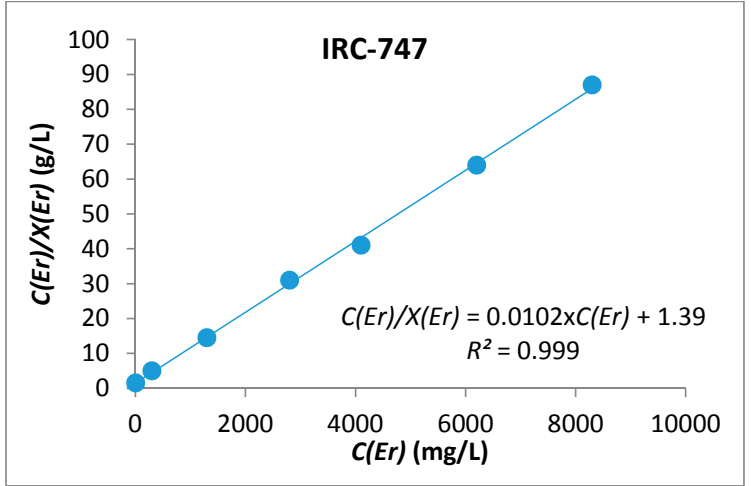

(a)

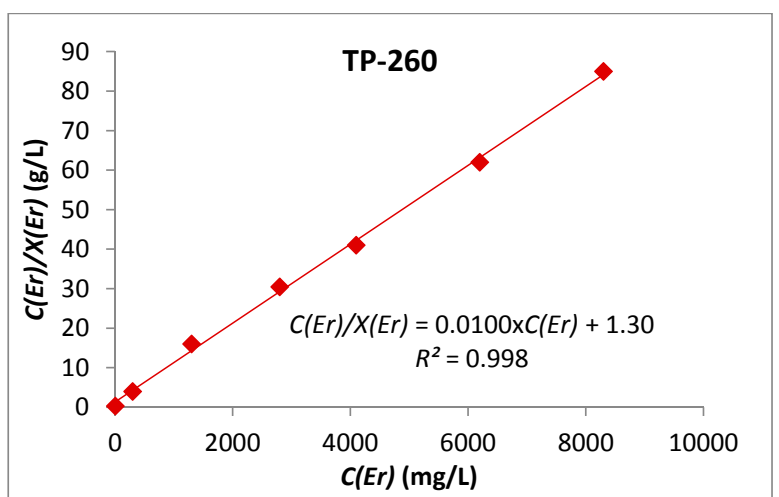

(b)

Figure 7. Langmuir adsorption isotherm for Er(III) with IRC-747 (a) and TP-260 (b).

\subsection{Extraction Kinetics with IRC-747 and TP-260}

In this section, the REE extraction kinetics from the genuine J0 solution (see Table 2) are presented in Figures 8 and 9, corresponding respectively to the IRC-747 and TP-260 resins. The experimental protocol is mentioned in Section 3.8. The concentrations of $C_{M}$ in REE have been measured by ICP-AES at the outlet of the columns for each bed volume BV after having passed the real phosphoric acid through the resin (see Figures 8a and 9a). The corresponding extraction yields expressed as $Y_{M}$ are reported on Figures $8 b$ and $9 b$.

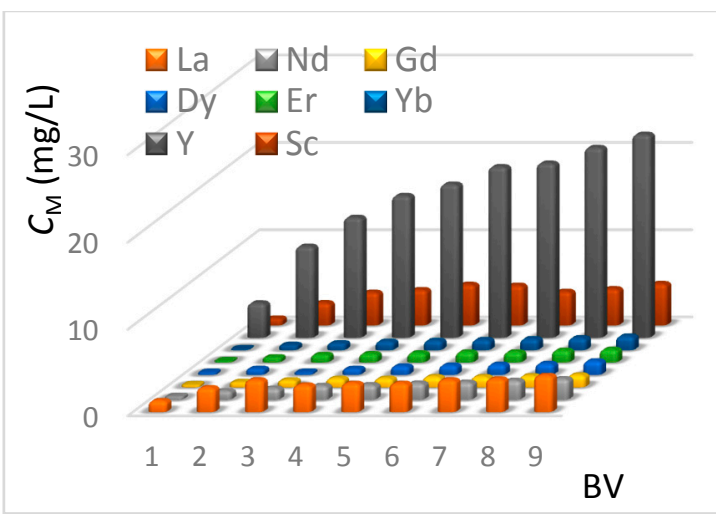

(a)

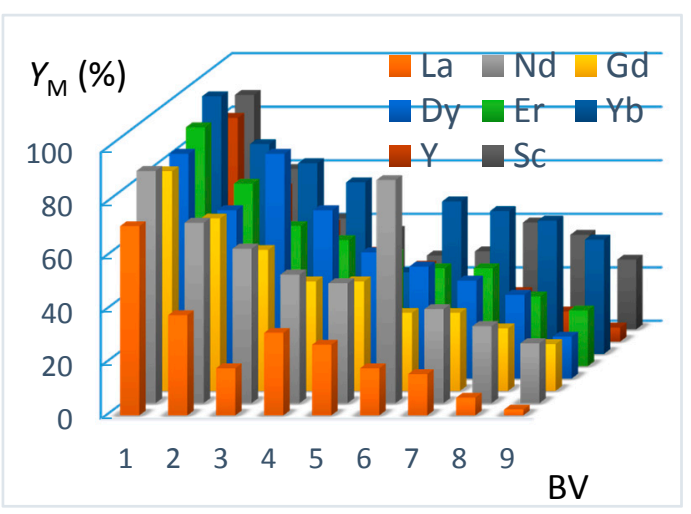

(b)

Figure 8. (a) Concentrations of REE at the outlet of the TP-260 column as a function of bed volume $(\mathrm{BV}=50 \mathrm{~mL}$, flowrate $=5 \mathrm{~mL} / \mathrm{min})$. Genuine J0 solution. (b) Extraction yields of REE at the outlet of the TP-260 column as a function of bed volume $(\mathrm{BV}=50 \mathrm{~mL}$, flowrate $=5 \mathrm{~mL} / \mathrm{min})$. Genuine J0 solution.

The extraction results using TP-260 resin show that more than $84 \%$ recovery of the total REE contained in phosphoric acid is achieved for the first bed volume. Ytterbium, erbium, scandium, and yttrium present the highest yield of extraction, while lanthanum represents the lowest yield of extraction. This is consistent with batch tests done before (see Section 4.2). Concerning the second bed volume passing through the resin, we can notice that the extraction efficiency is $30 \%$ lower for the REE, and at the ninth bed volume, the extraction yield is $13 \%$, which shows that the resin is almost saturated. 


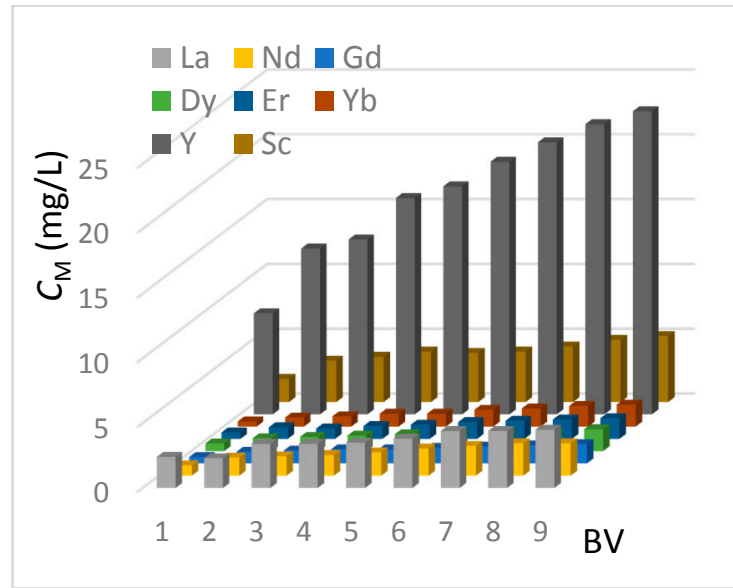

(a)

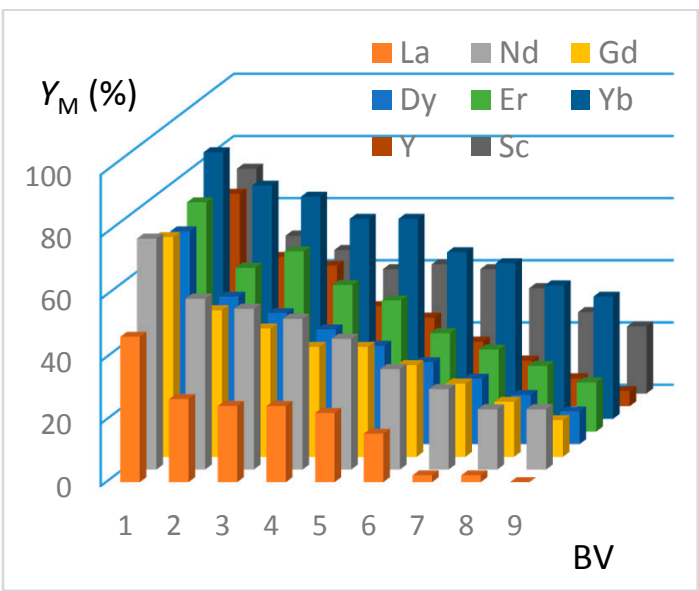

(b)

Figure 9. (a) Concentrations of REE at the outlet of the IRC-747 column as a function of the number of bed volume passed (BV $=50 \mathrm{~mL}$, flowrate $=5 \mathrm{~mL} / \mathrm{min}$ ). (b) Extraction yields of REE at the outlet of the IRC-747 column as a function of the number of bed volume passed (BV $=50 \mathrm{~mL}$, flowrate $=5 \mathrm{~mL} / \mathrm{min}$ ).

As in the case of TP-260 resin, the extraction efficiency is the highest for ytterbium, neodymium, erbium, and yttrium but values are somewhat lower: around 70\% are recovered with IRC-747 for the first bed volume passing through the resin, instead of $84 \%$ for TP-260. For both resins, lanthanum is the less extracted element. The results also show that the resin is saturated with lanthanum within the 8 th bed volume.

A comparison between the kinetics of extraction of TP-260 and IRC-747 is shown in Figure 10a where $\mathrm{F}$ denotes the total REE normalized concentration at time $\mathrm{t}$ expressed as the ratio of the fixed total REE concentration at the outlet of the resin to the initial total REE concentration at the inlet of the resin. $\mathrm{F}$ is the fractional attainment of equilibrium adsorption at time $t$.

The adsorption onto ion exchange resins must be considered as a liquid-solid phase reaction, which includes several steps [21,22]:

- The diffusion of ions from the solution to the resin surface whose rate $R$ can be described by:

$$
R=-\ln (1-F)=k t
$$

- The diffusion of ions within the solid resin whose rate $\mathrm{R}$ can be described by:

$$
R=-\ln \left(1-F^{2}\right)=k t
$$

- $\quad$ And the chemical reaction between ions and functional groups (of the resin).

When the adsorption of metal ion involves mass transfer accompanied by chemic al reaction (also referred to as the moving boundary model) the rate equation $\mathrm{R}$ is given by:

$$
R=3-3(1-F)^{2 / 3}-2 F=k t
$$

All these models have been compared against experimental data; it appears that the best fit is obtained when the metal uptake is controlled by the moving boundary particle diffusion model during the first $80 \mathrm{~min}(8 \mathrm{BV}$ ) for TP-260 and $70 \mathrm{~min}$ for IRC-747 (Figure 10b). 


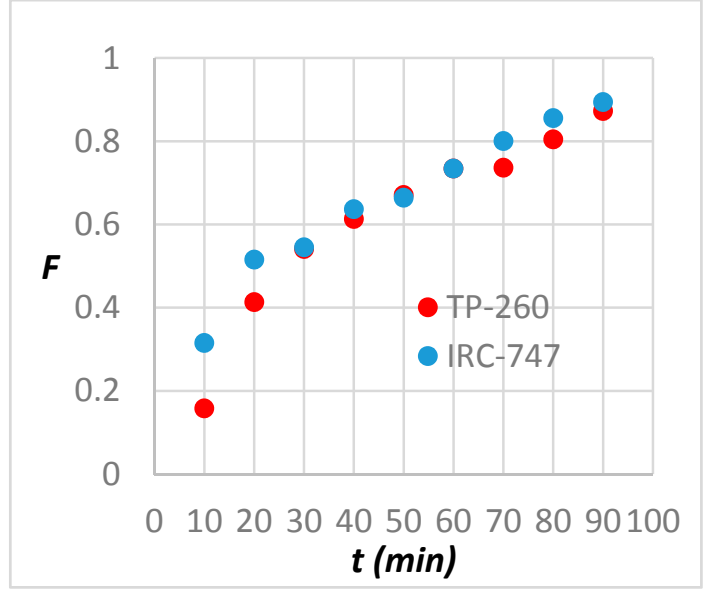

(a)

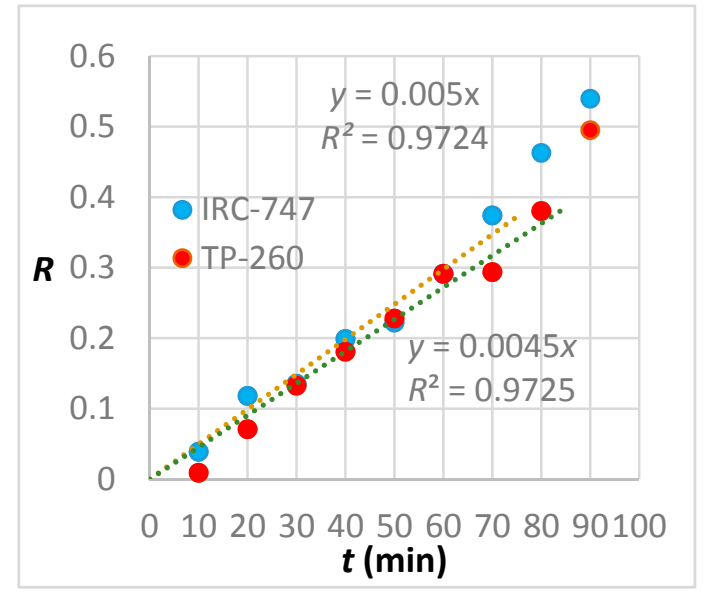

(b)

Figure 10. (a) Plot of the total REE adsorption on Lewatit TP260 and Amberlite IRC-747 resins. (b) Plot of moving boundary particle diffusion model for the total REE adsorption on Lewatit TP260 and Amberlite IRC-747 resins.

In Equation (3), $k$ is given by the expression:

$$
k=\frac{6 D_{r} C_{M-i n i}}{\mathrm{a} r_{0}^{2} C_{M-i n i}^{s}}
$$

where $D_{r}$ represents the diffusion coefficient in the resin bead $\left(\mathrm{m}^{2} / \mathrm{s}\right), r_{0}$ is the particle radius $(\mathrm{m})$, $C^{S}{ }_{M-i n i}$ is the concentration $(\mathrm{mg} / \mathrm{L})$ of solid reactant at the bead's unreacted core and a is the stoichiometric coefficient.

\subsection{Elution Conditions in Carbonate or Sulfuric Media}

The objective here is to evaluate different aqueous phase compositions for the quantitative and if possible selective elution of extracted cations. In order to be close to an industrial elution process, the protocol has consisted first in washing and drying the resin powder overnight at $60{ }^{\circ} \mathrm{C}$ after filtration $(0.2 \mu \mathrm{m})$ and then in contacting the resin containing cations with aqueous elution solution at $25{ }^{\circ} \mathrm{C}$. From economic considerations, this elution solution must be either a by-product of the phosphoric acid production or sufficiently cheap. Carbonate and sulfuric acid solutions have thus been considered here instead of concentrated hydrochloric acid for example.

This elution was carried out in $15 \mathrm{~mL}$ tubes containing $50 \mathrm{mg}$ of loaded resins with REOCP solution. These resins have been previously dried overnight in an oven at $60{ }^{\circ} \mathrm{C}$ and put in contact during $3 \mathrm{~h}$ with $10 \mathrm{~mL}$ of stirred solutions of sodium carbonate $1 \mathrm{~mol} / \mathrm{L}$ or sulfuric acid 9 and $18 \mathrm{~mol} / \mathrm{L}$. These tubes were kept at a constant temperature of $25^{\circ} \mathrm{C}$. All aqueous phases were analyzed by ICP-AES. The results are expressed as a yield of elution (i.e., the ratio of actual eluted mass of cations to the mass of cations initially fixed per gram of resin) and are illustrated in Table 3 following the two modes of calculation (Min: resin mineralization. Aq: aqueous phases). The deviation between both methods is within the margins of error of these protocols.

From that table it appears that even at low concentrations (i.e., $<10 \%$ ), the elution efficiency of iron makes the concentration of this impurity in the eluting solution always bigger by an order of magnitude than the concentration of eluted REE. Thus, from an engineering point of view the simultaneous extraction and separation of iron and REE from the high concentrated OCP phosphoric acid appear to be not feasible with IRC 747 and TP-260 resins and low-cost carbonates or sulfuric acid eluting solutions. 
Table 3. Elution yields in sodium carbonate or sulfuric acid of the elements from resins previously contacted with the REOCP solution. Aq: calculations based on aqueous phases. Min: calculations based on solid mineralization $\left(V_{\mathrm{Aq}}=10 \mathrm{~mL}, m_{\text {resin }}=50 \mathrm{mg}\right.$, stirring $\left.3 \mathrm{~h}, \mathrm{~T}=25^{\circ} \mathrm{C}\right)$.

\begin{tabular}{|c|c|c|c|c|c|c|c|}
\hline \multirow{3}{*}{$\begin{array}{c}\text { Name of Resin } \\
\text { Eluting Solution } \\
Y_{M}, R_{M} \text { Elution }(\%)\end{array}$} & \multirow{2}{*}{\multicolumn{2}{|c|}{$\begin{array}{c}\text { IRC-747 } \\
\mathrm{H}_{2} \mathrm{SO}_{4} 9 \mathrm{M}\end{array}$}} & \multirow{2}{*}{\multicolumn{2}{|c|}{$\begin{array}{c}\text { IRC-747 } \\
\mathrm{Na}_{2} \mathrm{CO}_{3} 1 \mathrm{M}\end{array}$}} & \multirow{2}{*}{\multicolumn{2}{|c|}{$\begin{array}{c}\mathrm{TP}-260 \\
\mathrm{Na}_{2} \mathrm{CO}_{3} 1 \mathrm{M}\end{array}$}} & \multirow{3}{*}{$\begin{array}{c}\mathrm{TP}-260 \\
\mathrm{H}_{2} \mathrm{SO}_{4} 18 \mathrm{M} \\
\mathrm{Aq}\end{array}$} \\
\hline & & & & & & & \\
\hline & $\mathrm{Aq}$ & Min & $\mathrm{Aq}$ & Min & $\mathrm{Aq}$ & Min & \\
\hline La & 39 & 34 & 25 & 30 & 20 & 15 & 72 \\
\hline Nd & 36 & 31 & 47 & 47 & 45 & 41 & 68 \\
\hline $\mathrm{Gd}$ & 44 & 36 & 60 & 46 & 51 & 46 & 79 \\
\hline Dy & 36 & 34 & 58 & 51 & 57 & 43 & 80 \\
\hline $\mathrm{Er}$ & 32 & 28 & 68 & 55 & 70 & 56 & 79 \\
\hline $\mathrm{Yb}$ & 29 & 26 & 66 & 56 & 63 & 53 & 78 \\
\hline $\mathbf{Y}$ & 30 & 29 & 65 & 45 & 61 & 43 & 78 \\
\hline Sc & 0 & 0 & 50 & 43 & 36 & 32 & 34 \\
\hline Al & 9 & 9 & 30 & 25 & 31 & 29 & 0 \\
\hline $\mathrm{Ca}$ & 48 & 68 & 65 & - & 75 & - & 3 \\
\hline $\mathrm{Fe}$ & 4 & 3 & 9 & 7 & 11 & 8 & 8 \\
\hline Mg & 80 & 15 & 14 & 2 & 19 & 18 & 16 \\
\hline V & 35 & 26 & 100 & 81 & 106 & 92 & 0 \\
\hline $\mathrm{Zn}$ & 83 & - & - & - & - & - & 79 \\
\hline
\end{tabular}

\section{Conclusions}

Among commercially available chelating ion exchange resins, IRC-747 and TP-260 appears to be particularly interesting for the extraction of REE from the high concentrated phosphoric acid (about $4 \mathrm{~mol} / \mathrm{L}$ ) produced by OCP due to their highest affinity for the metallic cations. Even if the sorption mechanisms are not understood, the influence of the atomic number and the ionic radius of the REE on the sorption affinity result in extraction yields that range from 20 to $60 \%$ and even about $80 \%$ for scandium. The adsorption of erbium (III) from pure $4 \mathrm{~mol} / \mathrm{L}$ phosphoric acid can be described by the Langmuir isotherm and leads to a maximum adsorption capacity estimated to be $1.8 \mathrm{meq} / \mathrm{g}$ for both resins. This value is similar to the total mass of iron fixed in the resins when put in contact with the OCP phosphoric acid. The capacity of the TP-260 and IRC-747 resins used for the extraction of REE from concentrated phosphoric acid solutions are thus far larger from other resins tested in the literature. However, the uptake of competitive pollutants, among which iron and aluminum appear to be the most interfering, reduces the REE adsorption by a factor of 4 . The elution procedure using high concentrated sulfuric acid enables the recovery of a large fraction of REE (around $80 \%$ except for scandium at around 30\%); however, even if the elution yield for iron is much lower $(<10 \%)$ the resulting elution solution needs to be further processed for the recovery of a pure REE concentrate. Furthermore, the build-up in iron inside the resin bed will also keep growing during the extraction/elution cycles. It is then mandatory to find another eluting system, for example based on a more expensive but selective complexing agent for REE such as diglycolamide.

Also, the kinetics of the total REE uptake by IRC 747 and TP 260 from a genuine phosphoric acid solution have been tested against different model expressions. The data appear to be best explained by the moving boundary particle diffusion model during the first 7 th or 8 th bed volume passed. Other operating conditions (flowrate, mass of resin ... ) should be required for validating such a behavior.

Finally, the preliminary OCP proprietary treatment has separated uranium and thorium from the produced phosphoric acid but the presence of other metallic impurities at relatively high concentration are likely to limit the techno-economical interest of the chelating ion exchange processes. Complementary studies could be conducted in order to check whether iron (and aluminum) could be kinetically separated from REE, even if this solution seems to be difficult to implement at an industrial scale. Recent developments in solvent extraction (SX) in high concentrated phosphoric acid could 
overcome this obstacle due to the high separation factors between REE and iron(III) [23]. However, this solution has still to be validated at larger scales.

Author Contributions: Conceptualization, X.H., V.B., A.O., H.M. and D.D.; Methodology, X.H., V.B., P.D.N., A.O., D.D. and F.C.; Validation, X.H., P.D.N., A.O., H.M. and D.D.; Formal Analysis, V.B. and X.H. Investigation, X.H., P.D.N., F.C., A.O., H.M. and D.D.; Resources, X.H., P.D.N., V.B., A.O., H.M. and D.D.; Writing-Original Draft Preparation, X.H., P.D.N., A.O., H.M. and D.D.; Writing-Review \& Editing, V.B. and X.H. Visualization, V.B., X.H. and A.O. Supervision, V.B., A.O., D.D.; Project Administration, V.B, A.O., D.D.; Funding Acquisition, D.D., H.M., A.O. and V.B.

Funding: This research received no external funding.

Acknowledgments: The authors want to acknowledge OCP for financial support and an anonymous reviewer for their valuable comments. The authors also would like to acknowledge the support of national network Promethee.

Conflicts of Interest: The authors declare no conflict of interest.

\section{References}

1. Soldenhoff, K.; Tran, M.T.; Griffith, C. Recovery of Uranium from Phosphoric by Ion Exchange. In Proceedings of the 2009 IAEA Technical Meeting-Uranium from Unconventional Resources, Vienna, Austria, 22-26 June 2009.

2. Kim, H.; Eggert, R.G.; Carlsen, B.W.; Dixon, B.W. Potential uranium supply from phosphoric acid A U.S. analysis comparing solvent extraction and Ion exchange recovery. Resour. Policy 2016, 49, 222-231. [CrossRef]

3. Michel, P. Les Techniques de L'industrie Minérale; Société de L'industrie Minérale: Paris, France, 2006; Volume 32, pp. 95-102.

4. Cote, D.B.G.; Mokhtari, H.; Courtaud, B.; Moyer, B.A.; Chagnes, A. Recovery of Uranium from Wet Phosphoric Acid by Solvent Extraction Processes. Chem. Rev. 2014, 114, 12002-12023.

5. Volkman, Y. Recovery of Uranium from Phosphoric Acid by Ion Exchange; Report IAEA-TECDOC-533; IAEA: Vienna, Austria, 1987; pp. 59-68.

6. Mashkovtsev, M.; Botalov, M.; Smyshlyaev, D.; Pajarre, R.; Kangas, P.; Rychkov, V.; Koukkari, P. Pilot-scale recovery of rare earths and scandium from phosphogypsum and uranium leachates. In Proceedings of the 2016 Mineral Engineering Conference, Swieradow-Zdroj, Poland, 25-28 September 2016.

7. Page, M.J.; Soldenhoff, K.; Ogden, M.D. Comparative Study of the Application of Chelating Resins for Rare Earth Recovery. Hydrometallurgy 2017, 169, 275-281. [CrossRef]

8. Helfferich, F. Ion Exchange; McGraw-Hill: New York, NY, USA, 1962.

9. Reddy, B.R.; Kumar, J.R. Rare Earths Extraction, Separation, and Recovery from Phosphoric Acid Media. Solvent Extr. Ion Exch. 2016, 34, 226-240. [CrossRef]

10. Quinn, J.E.; Soldenhoff, K.H.; Stevens, G.W.; Lengkeek, N.A. Solvent extraction of rare earth elements using phosphonic/phosphinic acid mixtures. Hydrometallurgy 2015, 157, 298-305. [CrossRef]

11. Nesterenko, P.N.; Zhukova, O.S.; Shpigun, O.A.; Jones, P. Synthesis and Ion-Exchange Properties of Silica Chemically Modified with Aminophosphonic Acid. J. Chromatogr. A 1998, 813, 47-53. [CrossRef]

12. Radhika, S.; Nagaraju, V.; Kumar, B.N.; Kantam, M.L.; Reddy, B.R. Solid-liquid extraction of Gd(III) and separation possibilities of rare earths from phosphoric acid solutions using Tulsion CH-93 and Tulsion CH-90 resins. J. Rare Earths 2012, 30, 1270-1275. [CrossRef]

13. Kumar, B.N.; Radhika, S.; Reddy, B.R. Solid-liquid extraction of heavy rare-earths from phosphoric acid solutions using Tulsion CH-96 and T-PAR resins. Chem. Eng. J. 2010, 160, 138-144. [CrossRef]

14. Cheira, M.F. Characteristics of uranium recovery from phosphoric acid by an aminophosphonic resin and application to wet process phosphoric acid. Eur. J. Chem. 2015, 6, 48-56. [CrossRef]

15. Kabay, N.; Demircioglu, M.; Yayh, S.; Gunay, E.; Yuksel, M.; Saglam, M.; Streat, M. Recovery of Uranium from Phosphoric Acid Solutions Using Chelating Ion-Exchange Resins. Ind. Eng. Chem. Res. 1998, 37, 1983-1990. [CrossRef]

16. Flahaut, J. Les éléments des Terres Rares; Masson: Paris, France, 1969.

17. Reddy, B.R.; Kumar, B.N.; Radhika, S. Solid Liquid Extraction of Terbium from Phosphoric Acid Medium using Bifunctional Phosphinic Acid Resin Tulsion CH 96. Solvent Extr. Ion Exch. 2009, 27, 695-711. [CrossRef]

18. Bunus, F.; Dumitrescu, R. Simultaneous extraction of rare earth elements and uranium from phosphoric acid. Hydrometallurgy 1992, 28, 331-338. [CrossRef] 
19. Li, D. A review on yttrium solvent extraction chemistry and separation process. J. Rare Earths 2017, 35, 107-119. [CrossRef]

20. Ochsentihn-Petropulu, M.; Lyberopulu, T.; Parissakis, G. Selective separation and determination of scandium from yttrium and lanthanides in red mud by a combined ion exchange/solvent extraction method. Anal. Chim. Acta 1995, 315, 231-237. [CrossRef]

21. Bao, S.; Hawker, W.; Vaughan, J. Scandium Loading on Chelating and Solvent Impregnated Resin from Sulfate Solution. Solvent Extr. Ion Exch. 2018, 36, 100-113. [CrossRef]

22. Alguacil, F.J. A kinetic study of cadmium(II) adsorption on Lewatit TP260 resin. J. Chem. Res. 2003, 3, 144-146. [CrossRef]

23. Rey, J.; Atak, S.; Dourdain, S.; Arrachart, G.; Berthon, L.; Pellet-Rostaing, S. Synergistic Extraction of Rare Earth Elements from Phosphoric Acid Medium using a Mixture of Surfactant AOT and DEHCNPB. Solvent Extr. Ion Exch. 2017, 35, 321-331. [CrossRef]

(C) 2018 by the authors. Licensee MDPI, Basel, Switzerland. This article is an open access article distributed under the terms and conditions of the Creative Commons Attribution (CC BY) license (http:/ / creativecommons.org/licenses/by/4.0/). 